\section{Research Square}

\title{
Spatial Distributions and Determinants of High-risk Fertility Behavior among Women in Ethiopia: Further Analysis from 2016 Ethiopia Demographic Health Survey
}

\section{Zemenu Tadesse Tessema University of Gondar \\ Koku Sisay Tamirat ( $\nabla$ kokusisay23@gmail.com ) \\ University of Gondar}

Department of Epidemiology and Biostatistics, Institute of Public Health, College of Medicine and health science,

\section{Research article}

Keywords: High-risk fertility behavior, spatial distributions, determinants, Ethiopia

Posted Date: March 5th, 2020

DOI: https://doi.org/10.21203/rs.3.rs-15616/v1

License: (c) (i) This work is licensed under a Creative Commons Attribution 4.0 International License. Read Full License 


\section{Abstract}

Background: High-risk fertility behavior associated with numerous unfavorable child and maternal health outcomes such as chronic undernutrition, anemia, and child mortality. Although different studies have been conducted to assess the magnitude and effects of high-risk fertility behaviors, there are limited shreds of evidence about the geographical distributions and determinants in Ethiopia. Therefore, this study aimed to assess the spatial distributions and determinants of high-risk fertility behavior among reproductive-age women in Ethiopia.

Method: This study was based on secondary data analysis from the 2016 Ethiopia Demography and Health Survey. Information about 11,022 women who gave birth five years preceding the survey were extracted from the kid's record (KR)

file. For the spatial analysis ArcGIS 10.6 and Sat Scan ${ }^{\mathrm{TM}}$ 9.6, were used and for multilevel analysis, STATA 14.1 was used. Mixed effect Multivariable multilevel logistic regression model was fitted to identify determinants of high-risk fertility behavior.

Result: More than three fourth $(76.5 \%)$ with $95 \% \mathrm{Cl}(75.1$ to 77.1$)$ women had high-risk fertility behavior. From the spatial analysis, high-risk fertility behavior in Ethiopia geographically varies, the eastern and northern parts of the country such as Somalia and Tigray had an increased risk of fertility behavior. Primary education ( $\mathrm{AOR}=0.71,95 \% \mathrm{Cl}: 0.63$ to 0.80 ) and secondary ( $A O R=0.73 ; 95 \% \mathrm{Cl}: 0.60$ to 0.89$)$, not ever used contraceptive ( $A O R=1.25,95 \% \mathrm{Cl}: 1.121 .40)$, unwanted pregnancy $(A O R=1.40,95 \% \mathrm{Cl}: 1.23$ 1.59), no $A N C$ visit $(A O R=1.19,95 \% \mathrm{Cl}: 1.051 .35)$, rural-dwelling $(A O R=1.26,95 \% \mathrm{Cl}$ : 1.041 .51 ), regions of Ethiopia [Somalia ( $A O R=1.70,95 \% \mathrm{Cl}: 1.242 .32)$ and Amhara (AOR=0.72,95\%Cl:0.53 0.96)] were determinants of high risk fertility behavior.

Conclusion: High-risk fertility behavior was significantly higher and geographical variations also noticed and the eastern and northern parts of the country were the hot spot areas. Education, rural residence, unwanted pregnancies, No ANC visit, and contraceptive use were determinants of high-risk fertility behavior. This suggests that areas with high-risk fertilities need special interventions to avert related complications.

\section{Background}

Maternal and child mortality is the main public health problem worldwide and it is the major health concern in developing countries such as Africa and Asia[1]. Globally, 830 women die from preventable causes related to pregnancy and childbirth, of which $99 \%$ of all deaths occur in developing countries[2]. Ethiopia one of the countries with the highest maternal mortality ratio with 412 deaths per 100,000 live births according to 2016 EDHS reports, of which most of the deaths were attributed to high-risk fertility behavior [1-3]. The maternal mortality issue is under a sustainable development goal (SDG) targeted to reduce below 70 deaths per 100,000 live births at the end of $2030[4]$.

The global population is rapidly increasing and according to the 2016 report, the total fertility was 2.5 and 4.8 per woman globally and Ethiopia, respectively [5]. Fertility behavior of women characterized in relation to maternal age, birth spacing, and order which has an impact on the health of women and children [6, 7]. High-risk fertility behavior associated with numerous unfavorable child and maternal health outcomes such as chronic undernutrition, anemia, and child and maternal mortality [8-10].

Different studies showed that high-risk fertility behaviors are associated with chronic undernutrition and anemia among under-five children. In addition, these behaviors are also associated with adverse birth outcomes such as stillbirth, low birth weight and prematurity [9, 11-13]. As the birth interval got narrower (less than 24 months) the chance of child morality increased sharply compared to long spaced birth intervals [14]. The risk of infant mortality from teenage mothers was increased by $30 \%$ compared to those women who gave birth between the age of 20 and 30 years. The problem is higher in developing countries where health care services are inaccessible, low socio-economic conditions and high 
unmet family planning need $[8,11,12,15-17]$. In addition, early age women marriage is also another problem for high-risk fertility problems in Ethiopia and other low and middle-income countries[15].

Different factors are associated with high-risk fertility behavior such as socio-demographic characteristics (residence, religion, level of education and marital status) and reproductive health characteristics such as history of child death, facility delivery, and family panning utilizations are factors associated with high-risk fertility behavior [8, 10-12, 15-18]. Government and stakeholders made tremendous efforts such as increasing health services accessibility and coverage, providing maternal health services free of charge and postnatal care follow up for mothers for halting high-risk fertilities[19]. Although, different studies conducted to assess the magnitude and effects of high-risk fertility behaviors no study was conducted to assess the geographical distribution and determinants of these behaviors in Ethiopia.

Therefore, this study aimed to assess the spatial distributions and determinants of high-risk fertility behavior among reproductive-age women in Ethiopia. This study could help health care planners for evidence-based interventions and appropriate allocation of resources in hot spot areas.

\section{Methods}

\section{Study design, area and period:}

A cross-sectional study design was conducted using a nationally representative Ethiopian Demographic and Health Survey (EDHS) 2016 dataset. Ethiopia is the second-largest populous country located in the Horn of Africa from $3^{0}$ to $14^{0}$ and $33^{0}$ to $48^{0} \mathrm{E}$. The study was conducted from December to June 2016.

\section{Sources and study populations:}

Women age 15-49 years in the enumeration areas within five years before the survey in Ethiopia were the source population. 15,683 women aged 15-49 years were interviewed and 11,023 women included in the analysis. In the 2016 EDHS, a total of 645 clusters (EAs) (202 urban and 443 rural) were selected with a probability proportional to each EAs size and independent selection in each sampling stratum. Among the total of selected clusters with zero coordinates and clusters without a proportion, HRFB was excluded for the analysis. Finally, a total of (185 urban and 413 rural) clusters were used for this study. Among the selected clusters a total of 11,023 weighted women were included in this study. The recorded data were accessed at www.measuredhs.com on request with the help of ICF International, Inc.

\section{Data collection tools and procedures:}

Ethiopian Demographic and Health Survey data were collected by two-stage stratified sampling. Each region of the country was stratified into urban and rural areas, yielding 21 sampling strata. In the first stage, 645 EAs were selected with probability proportional to Enumeration Area size by independent selection in each sampling stratum. In the second stage of selection, a fixed number of 28 households per cluster were selected with an equal probability systematic sampling from the newly created household listing. The detail sampling procedure was available in the Ethiopian Demographic and Health Survey reports from Measure DHS website (www.dhsprogram.com).

\section{Outcome variable}

For this study, we considered three parameters, maternal age at the time of delivery, birth order and birth interval, to define the high-risk fertility behaviors. Three exposure variables were defined for this analysis. Any high-risk fertility behavior versus non-risk coded as $1 / 0$ respectively. The presence of any of the following four conditions was termed high-risk fertility behavior: (i) mothers aged less than 18 years at the time of delivery; (ii) mothers aged over 34 years at the time of delivery; (iii) latest child born less than 24 months after the previous birth; and (iv) latest child of order three or higher. We 
applied the definition of ' high-risk fertility behaviors' adopted by the 2016 EDHS(11). The dependent variable in this analysis was high-risk fertility behavior (proportion in the cluster).

\section{Predictor variables:}

Predictor variables for this study were demographic characteristics such as sex of a child, religion, educational level, occupation, wealth index, media exposure, residence and region and reproductive characteristics contraceptive use, wanted pregnancy, ANC follow up, stillbirth, and place of delivery

\section{Data processing and Analysis}

After data was cleaned and extracted, descriptive statistics and multivariable multi-level logistic regression were done using STATA 14.1, whereas, for spatial analysis, ArcGIS 10.6 and Sat Scan ${ }^{\text {TM }} 9.6$ was used. The data were weighted using cluster number, primary sampling unit, and strata before any statistical analysis to restore the representativeness of the survey and to tell the STATA to take into account the sampling design when calculating SEs.

\section{Spatial autocorrelation and hot spot analysis:}

Spatial autocorrelation (Global Moran's I) statistic measure was used to assess whether HRFB among reproductive-age women were dispersed, clustered, or randomly distributed in Ethiopia. Moran's I values close to -1 indicates the low proportion of HRFB and dispersed, close to +1 indicates clustered, and if Moran's I value zero indicates randomly distributed. A statistically significant Moran's I value $(p<0.05)$ had a chance to rejection of the null hypothesis which indicates the presence of spatial autocorrelation. Hot Spot Analysis (the Getis-Ord Gi* statistic) of the z-scores and significant $p$-values tells the features with either hot spot or cold spot values for the clusters spatially.

\section{Spatial interpolation:}

The spatial interpolation technique is used to predict HRFB proportion among reproductive-age women for unsampled areas in the country based on sampled EAs. For the prediction of unsampled EAs, we used deterministic and geostatistical Empirical Bayesian Kriging spatial interpolation techniques. Ordinal Kriging method of Gaussian distribution was used.

\section{Spatial scan statistics:}

We employed Bernoulli based model spatial scan statistics to determine the geographical locations of statistically significant clusters for HRFB using Kuldorff's SaTScan version 9.6 software (15). The scanning window that moves across the study area in which HRFB was taken as cases and no HRFB were taken as controls to fit the Bernoulli model. The default maximum spatial cluster size of $<50 \%$ of the population was used as an upper limit, allowing both small and large clusters to be detected, and ignored clusters that contained more than the maximum limit with the circular shape of the window. Most likely clusters were identified using p-values and likelihood ratio tests on the basis of the 999 Monte Carlo replications.

\section{Model Building:}

We fit four models, the null model without predictors, the model I with only individual-level variables, model II with only community-level variables, and model III both individual-level and community-level variables. These models were fitted by a STATA command "xtmelogit" for the identification of predictors with the outcome variable. For model comparison, we used the log-likelihood ratio (LLR) and Akakian Information Criteria (AIC) test. The highest log-likelihood and the lowest AIC wins the best fit model. 


\section{Parameter Estimation Methods}

In the multilevel multivariable logistic regression model, fixed effect estimates measure the association between the odds of HRFB of individual and community level factors with a 95\% confidence interval. The random effect measures variation HRFB across clusters expressed by Intraclass Correlation (ICC) quantifies the degree of heterogeneity of HRFB between clusters, Percentage Chane in Variance (PCV) the proportion of the total observed individual variation in-HRFB that is attributable to between cluster variations and Median Odds Ratio (MOR) median value of the odds ratio between the cluster at HRFB and cluster at lower risk of HRFB when randomly picking out two clusters (EAs)

\section{Ethics approval and consent to participate}

Ethical clearance was obtained from measure DHS through filling requesting form for accessing data. The data used in this study are publicly available, aggregated secondary data that hasn't any personal identifying information that can be linked to study participants. The confidentiality of data was maintained anonymously.

\section{Result}

\section{Socio-demographic characteristics of respondents}

A total of 11,022 women who gave birth in the preceding five years before the survey were included in the final analysis. The median age of women was 28 with an interquartile range of 25 to 34 years, about half (53\%) of them aged between 25 and 34 years. The majority (89\%) of women were rural dwellers, most (93.1\%) were married, and about $41.4 \%$ and $34.2 \%$ were Muslim and Orthodox followers, respectively. Two-third (66.1\%) of women had not attended any formal education and $59.3 \%$ of them had no occupation (Table 1 ).

\section{Reproductive characteristics and high-risk fertility behavior}

This study revealed that $76.5 \%$ with $(95 \% \mathrm{Cl}$ : 75.1 to 77.1$)$ of women had high-risk fertility behavior, of which $31.4 \%$ were in single risk category, $27.1 \%$ of them had a birth interval of less than 24 months and about $45.1 \%$ of women were categorized in multiple high-risk category.

Out of total mothers who participated $43.1 \%$ of them were grand multiparous, the majority (75\%) of pregnancy forth recent birth were wanted of which three-fourth (74.4\%) of mothers had antenatal care follow up for their recent child. The majority (98.1\%) of women gave birth vaginally for their recent child, of which $72.5 \%$ delivered at home, and $8.5 \%$ of them had experience of stillbirth. About $30.1 \%$ of women had anemia during pregnancy (Table 2 ).

\section{Spatial autocorrelation of High-Risk Fertility Behavior in Ethiopia}

This study revealed that the spatial distribution of HRFB was found to be non-random in Ethiopia with Global Moran's I $0.113(p<0.001)($ Fig1)

The clustered patterns (on the right sides) show high rates of HRFB occurred over the study area. The outputs have automatically generated keys on the right and left sides of each panel. Given the z-score of 3.78 indicated that there is less than $1 \%$ likelihood that this clustered pattern could be the result of random chance. The bright red and blue colors to the end tails indicate an increased significance level. The table shows that the observed value is greater than the expected value and P-value is $<0.05$, it is statistically significant and nonrandom distribution of high-risk fertility behavior in the population.

Incrementa Spatial I Autocorrelation among reproductive-age women in Ethiopia. 
To determine spatial clustering for HRFB, global spatial statistics were estimated using Moran's I value. As shown in the figure below a statistically significant z-scores indicate at $166 \mathrm{Km}$ distances where spatial processes promoting clustering are most pronounced. The incremental spatial Autocorrelation indicates that a total of 10 distance bands were detected with a beginning distance of 121813 meters. The spatial distribution of HRFB among reproductive-age women in Ethiopia was found non-random with a Global Maran's I was 0.11 and p-value 0.0001 . The $z$-score of 3.77 , there is a less than $1 \%$ likelihood that this high-clustered pattern could be the result of random chance. (Fig 2)

\section{The spatial autocorrelation by a function of distance}

The spatial autocorrelation by a function of distance was a peak of 166149.46 meters and significant at a z-score value of 6.868081. so that this distance helps to fix the band for neighbors(conceptualization of relationships) during hot spot analysis to identify the hot and cold areas for high-risk fertility behavior across regions of Ethiopia (Fig.2)

\section{Hot spot (Getis-Ord Gi) analysis:}

As shown in the figure below, the red color indicates the more intense clustering of high (hot spot) proportion HRFB preceding the survey period. A high proportion of HRFB was clustered at the Somali and Afar region of Ethiopia. Whereas, Amhara, SNNPR and Addis Ababa regions of Ethiopia were less risk area. (Fig 3)

\section{Spatial Sat Scan analysis of High-risk fertility behavior among women across regions of Ethiopia, 2016}

Most likely (primary clusters) and secondary clusters of HRFB were identified. A total of 383 significant clusters were identified. Of these, 181 of them were most likely (primary) clusters and 102 were secondary clusters. The primary clusters' spatial window was located in the Somali, Eastern Oromia, Dire Dawa and Harari region which was centered at $5.848373 \mathrm{~N}, 43.527981 \mathrm{E}$ with $569.73 \mathrm{~km}$ radius, and Log-Likelihood ratio (LLR) of 65.24 , at $\mathrm{p}<0.001$. It showed that women within the spatial window had 1.13 times higher risk of HRFB than women outside the window (Table 3). The secondary clusters' spatial window was typically located in the central part of the Amhara region. Which was centered at $11.287790 \mathrm{~N}, 38.406887 \mathrm{E}$ with $71.42 \mathrm{~km}$ radius, and LLR of $9.46 \mathrm{at}$-value 0.032 . It showed that women within the spatial window had a 1.16 times higher risk of HRFB than women outside the window (Fig.4).

\section{Interpolation of high-risk fertility behavior}

The predicted high-risk fertility behavior over the area increases from green to red-colored areas. The red color indicates high-risk areas of predicted HRFB and the green color indicates the predicted low fertility behavior risk areas. The Somali region, the Afar region, Eastern parts of the Oromia region, and center parts of the Beneshangul Region were predicted as more risky areas compared to other regions. Continuous images produced by interpolating (Kriging interpolation method) HRFB among women. The red color indicates the predicted high-risk areas and green color indicates fewer risk areas of HRFB (Figure.5).

\section{Individual and community-level determinants of high-risk fertility behavior}

The results of multilevel logistic regression for the individual-level and community-level variables are presented in Table 4. In the full model in which all individual-level and community-level factors are included education status of women, ANC visit during pregnancy, contraceptive utilization, wanted pregnancy, residence and region were factors significantly associated with high-risk fertility behavior.

Women who attend primary or secondary education, the odds of high-risk fertility behavior were decreased by 29 and 27 $\%$, respectively compared to those who had no formal education ( $A O R=0.71 ; 95 \% \mathrm{Cl} \quad 0.63$ to 0.80 ) and (AOR=0.73; $95 \%$ $\mathrm{Cl}: 0.60$ to 0.89$)$. Those women had not used contraceptives previously, the odds of high-risk fertility behavior were increased by $25 \%$ compared to those who had used contraceptives ( $A O R=1.25 ; 95 \% \mathrm{Cl} 1.12$ to 1.40 ). Those women who 
had unwanted pregnancies, the odds of high-risk fertility behavior were $40 \%$ more likely compared to those who had wanted pregnancies $(A O R=1.40 ; 95 \% \mathrm{Cl} 1.23$ to 1.59). Women who had no antenatal care visits for their recent child, the odds of high-risk fertility behavior were $19 \%$ more likely compared who had follow-ups (AOR=1.19; $95 \% \mathrm{Cl} 1.05$ to 1.35$)$.

Moreover, living in a rural area was also associated with a $26 \%$ higher odds of high-risk fertility behavior among women of reproductive age than women who were urban residents ( $A O R=1.26 ; 95 \% \mathrm{Cl} 1.04$ to 1.51$)$. Higher odds of high-risk fertility behavior were observed in the Somali regional state (AOR=1.70; 95\% $\mathrm{Cl}$ : 1.24 to 2.32) compared with Addis Ababa. However, the odds of high-risk fertility behavior among women were lower in the Amhara region compared with Addis Ababa (AOR= $0.7295 \% \mathrm{Cl}$ : 0.53 to 0.96$)$ (Table 4).

The high-risk fertility behavior prevalence rate was not similarly distributed across the communities. About $5.4 \%$ of the variance in the odds of high-risk fertility behavior in women could be attributed to community-level factors, as calculated by the ICC based on estimated intercept component variance and also the variation was statistically significant(p-value $<0.001)$. After adjusting for individual-level and community-level factors, the variation in high-risk fertility behavior across communities remained statistically significant. About $1.18 \%$ of the odds of high-risk fertility behavior variation across communities was observed in the full model (model 4). Moreover, the MOR indicated that high-risk fertility behavior was attributed to community-level factors. The MOR for high-risk fertility behavior was 1.50 in the empty model (model 1); this showed that there was variation between communities (clustering) since MOR was 1.5 times higher than the reference $(M O R=1)$. The unexplained community variation in high-risk fertility behavior decreased to MOR of 1.20 when all factors were added to the null model (empty model). This indicates that when all factors are included, the effect of clustering is still statistically significant in the full model (Table 4).

\section{Discussion}

This study revealed more than three fourth of women had high-risk fertility behavior of which $31.4 \%$ and $45.1 \%$ of them in single and multiple risk categories, respectively. Furthermore, the birth interval of less than 24 months was the most common single risk on $27.4 \%$ of women. This finding was lower than a study conducted in the Afar region of Ethiopia (86.3\%). However, this finding was higher than 58\% of 2011 EDHS report [30], 34\% in Bangladesh DHS[20], (38.3\%) in Nepal[31] and 44.9\% in India [31]. The possible explanation for the observed discrepancies might be due to the fact that socio-demographic characteristics changes and increased intention of fertility in society. Specifically, when compared with Asian countries such as Nepal the socio-demographic characteristics are quite different and also the health system variations could be the reason. In addition, in Ethiopia, child marriage is higher which might be responsible for the increased magnitude of risky fertility behavior[32].

From the spatial analysis high-risk fertility behavior in Ethiopia geographically varies, the eastern part of the country such as Somalia and northern Tigray had an increased high-risk fertility behavior. This could be explained by the low family planning acceptance rate and child marriage are the possible explanations. According to the 2016 review of pieces of evidence, the Somalia region is among the top 50 hotspot areas for child marriage [32].

Those women who had attended primary and secondary school associated with decreased high-risk fertility behavior compared to those who had no formal education. This finding was consistent with the study result in Ethiopia, Nigeria and Nepal $[6,30,31,33]$. This could be due to the fact that those attend school had better knowledge and awareness about high-risk fertility behavior and lower probability of experiencing early marriage.

Women who had no ever used contraceptive associated with an increased occurrence of high-risk fertility behavior compared to those who had used. This finding is supported by other studies and evidence [15, 17]. One of the purposes of contraceptive use is spacing birth and decreasing unintended pregnancies which might affect the health of mother and 
child. One of the basic postnatal intervention is family planning service provision for mothers with the aim of spacing birth intervals [18].

Women who had a history of unwanted pregnancies were more likely to had high-risk fertility behavior compared to wanted pregnancies. This finding was consistent with other studies conducted in Nigeria [6]. Women who had experienced unwanted pregnancies is an indicator of low family planning accessibility.

Women who were rural dwellers were positively associated with high-risk fertility behavior compared to those urban dwellers. This finding was consistent with the study conducted in Ethiopia. Women in rural areas are highly disadvantaged in terms of reproductive health services besides low literacy levels in rural areas. This finding was consistent with the previous study in Ethiopia [30]. Those women who no had ANC care follow-ups for their recent children were associated with increased risky fertility behavior. During ANC follow up in addition, to medical and clinical checkups for the mother and fetus, counseling about postnatal care including choice of family planning for the widening of intervals between births. Therefore not had ANC follow up during pregnancy may contribute to risk fertility behavior among reproductive-age women.

Compared to Addis Ababa women who reside in the Somalia region, high-risk fertility behavior was doubled, in contrast, women who live in the Amhara region high-risk fertility behavior were decreased. This might be explained due because of health service inaccessibility, low family planning acceptance rate due to community believes and myths from religious perspectives. Moreover, in the Somalia region, the community follows nomadic ways of life and difficult for health services in addition to a serious security problem. This finding was consistent with the findings of spatial analysis in the above-depicted figures.

This study has strengths of data were nationally representative, the multi-level analysis used to account cluster correlations and spatial analysis were also used for identifying hotspot areas for efficient interventions. However, this study has faced the following limitations firstly cross-sectional nature of the study affects the cause-effect relationship, secondly, health system characteristics were not assessed and finally the data this study had problems of recall bias such as a number of months for the birth interval.

\section{Conclusion}

High-risk fertility behavior was significantly higher and geographical variations also noticed and the eastern and northern parts of the country were the hot spot areas. Education, rural residence, unwanted pregnancies, ANC visits, and not used contraceptives were determinants of high-risk fertility behavior. This suggests that areas with high-risk fertilities need special interventions to avert related complications.

\section{Abbreviations}

ANC: Antenatal Care, AOR: Adjusted Odds Ratio, Cl: Confidence Interval, DHS: Demographic and Health Survey, EA: Enumeration Area, E: East, EDHS: Ethiopian Demographic and Health Survey, GIS: Geographical Information System, HH: High High, HL: High Low, ICC: Intra Class Correlation, Km: Kilometer, KR: Kids Record, LH, Low High, LL: Low Low, LLR: Likelihood Ratio, , MOR: Median Odds Ratio, N: North, PCV: Proportion of Cluster Variance, SE: Standard Error, SGD: Sustainable Development Goal, SNNP: Southern Nation: Nationality and People

\section{Declarations}

\section{Availability of data and materials}

The datasets used during the current study is available from the corresponding author 


\section{Funding}

We didn't receive external funds for this research.

\section{Acknowledgment}

We would like to thank the Ethiopian Central Statistics Agency for providing us with all the relevant secondary data used in this study. Finally, we would like to thank all who directly or indirectly supported us.

\section{Consent for publication}

Not applicable as there is no image or other confidentiality related issues.

\section{Competing interests}

The authors declared that they have no competing interests.

\section{Authors' contributions}

ZTT and KST conceived the study, involved in the study design, data analysis, drafted the manuscript and critically reviewed the manuscript. All authors read and approved the final manuscript.

\section{Authors' details}

Department of Epidemiology and Biostatics, Institute of Public Health, College of Medicine and Health Sciences, University of Gondar, Gondar, Ethiopia.

\section{References}

1. Hogan, M.C., et al., Maternal mortality for 181 countries, 1980-2008: a systematic analysis of progress towards Millennium Development Goal 5. The lancet, 2010. 375(9726): p. 1609-1623.

2. Alkema, L., et al., Global, regional, and national levels and trends in maternal mortality between 1990 and 2015, with scenario-based projections to 2030: a systematic analysis by the UN Maternal Mortality Estimation Inter-Agency Group. The Lancet, 2016. 387(10017): p. 462-474.

3. Central Statistical Agency, Ethiopia demographic and health survey 2016, in ORC Macro, Calverton, Maryland, USA. 2016.

4. Kumar, S., N. Kumar, and S. Vivekadhish, Millennium development goals (MDGS) to sustainable development goals (SDGS): Addressing unfinished agenda and strengthening sustainable development and partnership. Indian journal of community medicine: official publication of Indian Association of Preventive \& Social Medicine, 2016. 41(1): p. 1.

5. Tadesse, G., Women Empowerment and Their Reproductive Behaviour among Currently Married Women In Ethiopia. 2018, Addis Ababa University.

6. Adiri, F., et al., Fertility behaviour of men and women in three communities in Kaduna state, Nigeria. African Journal of Reproductive Health, 2010. 14(3): p. 97-105.

7. Asghar, M., B. Murry, and K.N. Saraswathy, Fertility behaviour and effect of son preference among the Muslims of Manipur, India. Journal of Anthropology, 2014. 2014.

8. Adhikari, R., Demographic, socio-economic, and cultural factors affecting fertility differentials in Nepal. BMC pregnancy and childbirth, 2010. 10(1): p. 19.

9. Balasch, J. and E. Gratacós, Delayed childbearing: effects on fertility and the outcome of pregnancy. Current Opinion in Obstetrics and Gynecology, 2012. 24(3): p. 187-193. 
10. Casterline, J.B. and R. Lazarus, Determinants and consequences of high fertility: a synopsis of the evidence. Addressing the Neglected MDG: World Bank Review of Population and High Fertility, World Bank publications, 2010.

11. Fall, C.H., et al., Association between maternal age at childbirth and child and adult outcomes in the offspring: a prospective study in five low-income and middle-income countries (COHORTS collaboration). The Lancet Global Health, 2015. 3(7): p. e366-e377.

12. Jonas, K., et al., Teenage pregnancy rates and associations with other health risk behaviours: a three-wave crosssectional study among South African school-going adolescents. Reproductive health, 2016. 13(1): p. 50.

13. Rutstein, S.O. and R. Winter, The effects of fertility behavior on child survival and child nutritional status: Evidence from the Demographic and Health Surveys 2006 to 2012. 2014.

14. Isabirye, A., The effects of high risk fertility behavior on child survival in Uganda. 2012, Makerere University.

15. Brown, W., et al. Impact of family planning programs in reducing high-risk births due to younger and older maternal age, short birth intervals, and high parity. in Seminars in perinatology. 2015. Elsevier.

16. Hasan, A., M.K. Singh, and A. Khan, Fertility behaviour and contraceptive use in urban slums of district Gorakhpur. International Journal Of Community Medicine And Public Health, 2017. 4(12): p. 4702-4705.

17. Rutstein, S.O. and R. Winter, Contraception needed to avoid high-fertility-risk births, and maternal and child deaths that would be averted. 2015: ICF International.

18. Singer Babiarz, K., et al., Family Planning and Fertility Behavior: Evidence from Twentieth Century Malaysia. Center for Global Development Working Paper, 2017(470).

19. Way, C., The millennium development goals report 2015. 2015: UN.

20. Rahman, M., A. Hosen, and M.A. Khan, Association between Maternal High-Risk Fertility Behavior and Childhood Morbidity in Bangladesh: A Nationally Representative Cross-Sectional Survey. The American journal of tropical medicine and hygiene, 2019: p. tpmd190221.

21. Raj, A., et al., The effect of maternal child marriage on morbidity and mortality of children under 5 in India: cross sectional study of a nationally representative sample. Bmj, 2010. 340: p. b4258.

22. Waldhör, T., The spatial autocorrelation coefficient Moran's I under heteroscedasticity. Statistics in Medicine, 1996. 15(7-9): p. 887-892.

23. Ord, J.K. and A. Getis, Local spatial autocorrelation statistics: distributional issues and an application. Geographical analysis, 1995. 27(4): p. 286-306.

24. Tsai, P.-J., et al., Spatial autocorrelation analysis of health care hotspots in Taiwan in 2006. BMC Public Health, 2009. 9(1): p. 464.

25. Kulldorff, M., A spatial scan statistic. Communications in Statistics-Theory and methods, 1997. 26(6): p. $1481-1496$.

26. Kulldorff, M., SaTScan user guide. StatScan, Boston, USA, 2006.

27. Guo, G. and H. Zhao, Multilevel modeling for binary data. Annual review of sociology, 2000. 26(1): p. 441-462.

28. Merlo, J., et al., A brief conceptual tutorial of multilevel analysis in social epidemiology: linking the statistical concept of clustering to the idea of contextual phenomenon. Journal of Epidemiology \& Community Health, 2005. 59(6): p. 443-449.

29. Merlo, J., et al., A brief conceptual tutorial on multilevel analysis in social epidemiology: interpreting neighbourhood differences and the effect of neighbourhood characteristics on individual health. Journal of Epidemiology \& Community Health, 2005. 59(12): p. 1022-1029.

30. Dejene, E.G.a.T., Correlates of High Risk Fertility Behaviour in Ethiopia: A Multilevel Analysis of the 2011 Ethiopian Demographic and Health Survey Data. Journal of Health, Medicine and Nursing, 2017. 39(ISSN 2422-8419).

31. Rahman, M., et al., Maternal high-risk fertility behavior and association with chronic undernutrition among children under age 5 y in India, Bangladesh, and Nepal: Do poor children have a higher risk? Nutrition, 2018. 49: p. 32-40. 
32. Marshall, E., et al., Child marriage in Ethiopia: A review of the evidence and an analysis of the prevalence of child marriage in hotspot districts. 2016, UNICEF Ethiopia and Overseas Development Institute (ODI). https://www ....

33. Kulu, H. and P.J. Boyle, High fertility in city suburbs: compositional or contextual effects? European Journal of Population/Revue européenne de Démographie, 2009. 25(2): p. 157-174.

\section{Tables}

Table 1: Socio-demographic characteristics of women who gave birth in the preceding five years before the survey in Ethiopia, $2016(n=11,022)$

\begin{tabular}{|c|c|c|c|}
\hline Characteristics & Category & Frequency & Percentage \\
\hline \multirow[t]{3}{*}{ Mother's age } & $15-24$ & 2446 & 22.2 \\
\hline & $25-34$ & 5842 & 53 \\
\hline & $35-49$ & 2734 & 24.8 \\
\hline \multirow[t]{2}{*}{ Sex of child } & Male & 5297 & 52 \\
\hline & Female & 5725 & 48 \\
\hline \multirow{4}{*}{ Religion } & Orthodox & 3772 & 34.2 \\
\hline & Muslim & 4561 & 41.4 \\
\hline & Protestant & 2329 & 21.1 \\
\hline & Others & 360 & 3.3 \\
\hline \multirow[t]{2}{*}{ Residence } & Urban & 1215 & 11 \\
\hline & Rural & 9807 & 89 \\
\hline \multirow{11}{*}{ Region } & Tigray & 716 & 6.5 \\
\hline & Afar & 114 & 1 \\
\hline & Amhara & 2072 & 18.8 \\
\hline & Oromia & 4851 & 44 \\
\hline & Somalia & 508 & 4.6 \\
\hline & Benishangul Gumuz & 121 & 1.1 \\
\hline & SNNP & 2296 & 20.8 \\
\hline & Gambela & 26 & 0.24 \\
\hline & Harari & 25 & 0.23 \\
\hline & Addis Ababa & 244 & 2.2 \\
\hline & Dire Dawa & 47 & 0.43 \\
\hline \multirow{4}{*}{ Educational status of mother } & No formal education & 7284 & 66.1 \\
\hline & Primary education & 2950 & 26.8 \\
\hline & Secondary education & 514 & 4.7 \\
\hline & Higher education & 274 & 2.5 \\
\hline \multirow[t]{4}{*}{ Educational status of the husband } & No formal education & 5077 & 48.5 \\
\hline & Primary education & 4115 & 39.3 \\
\hline & Secondary education & 798 & 7.6 \\
\hline & Higher education & 471 & 4.5 \\
\hline \multirow[t]{2}{*}{ Occupational status of women } & Working & 4896 & 44.4 \\
\hline & Not working & 6126 & 55.6 \\
\hline \multirow[t]{3}{*}{ Wealth index } & Poor & 5155 & 46.8 \\
\hline & Middle & 2280 & 20.7 \\
\hline & Rich & 3587 & 32.5 \\
\hline \multirow[t]{2}{*}{ Media exposure } & Yes & 10,035 & 91 \\
\hline & No & 987 & 9 \\
\hline
\end{tabular}

Table 2: Reproductive and high-risk fertility behavior of women who gave birth five years before the survey in Ethiopia, $2016(n=11,022)$ 


\begin{tabular}{|c|c|c|c|}
\hline Characteristics & Category & Frequency & Percentages \\
\hline \multirow[t]{2}{*}{ Wanted pregnancy } & Yes & 8279 & 75.1 \\
\hline & No & 2743 & 24.9 \\
\hline \multirow{2}{*}{ Had ANC follow up } & Yes & 8204 & 74.4 \\
\hline & No & 2818 & 25.6 \\
\hline \multirow[t]{2}{*}{ History of stillbirth } & Yes & 966 & 8.8 \\
\hline & No & 10056 & 91.2 \\
\hline \multirow[t]{4}{*}{ Anemia } & Severe & 157 & 1.5 \\
\hline & Moderate & 745 & 7 \\
\hline & Mild & 2321 & 21.8 \\
\hline & No anemia & 7416 & 69.7 \\
\hline \multirow[t]{2}{*}{ Place of delivery } & Home & 7997 & 72.5 \\
\hline & Health facility & 3025 & 27.5 \\
\hline \multirow[t]{3}{*}{ Parity } & Primiparous & 1434 & 13 \\
\hline & Multiparous & 4836 & 43.9 \\
\hline & Grand multiparity & 4752 & 43.1 \\
\hline \multirow[t]{3}{*}{ Birth order } & 1 & 2058 & 18.7 \\
\hline & $2-4$ & 4718 & 42.8 \\
\hline & $\geq 5$ & 4246 & 38.5 \\
\hline
\end{tabular}

Table 3: SaT Scan analysis of high-risk fertility behavior among women in the last five years in Ethiopia, 2016. 


\begin{tabular}{|c|c|c|c|c|c|c|c|}
\hline Cluster type & $\begin{array}{l}\text { Significant Enumeration } \\
\text { Areas(clusters) detected }\end{array}$ & $\begin{array}{l}\text { Coordinates } \\
\text { /Radius }\end{array}$ & Populations & Cases & RR & LLR & $\begin{array}{l}P \text { - } \\
\text { value }\end{array}$ \\
\hline Primary & 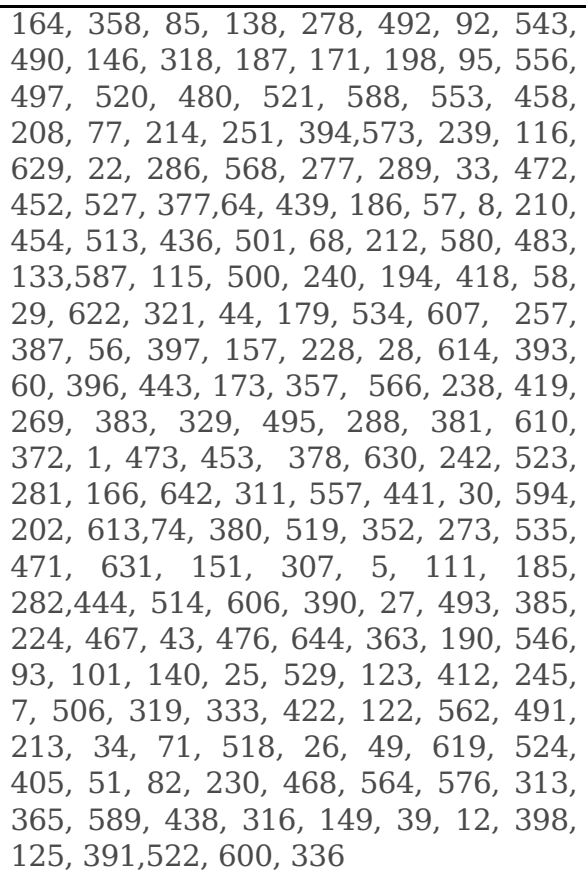 & $\begin{array}{l}(5.848373 \\
\mathrm{N}, \\
43.527981 \\
\mathrm{E}) / 569.73 \\
\mathrm{~km}\end{array}$ & 3450 & 2870 & 1.13 & 64.24 & $\begin{array}{l}< \\
0.001\end{array}$ \\
\hline Secondary & $\begin{array}{l}278,318,187,358,85,164, \\
556,480,492,543,138,490, \\
92,198,171,95,497,521, \\
588,146,553,286,458,520, \\
394,289,472,214,452,251, \\
208,573,239,116,22,568, \\
377,277,372,454,513,186, \\
527,33,68,501,580,436,64, \\
133,115,212,483,8,500, \\
587,240,29,418,58,439, \\
607,179,194,44,321,534, \\
257,56,397,210,157,228, \\
387,28,614,57393,60,396, \\
173,443,622,238,383,357, \\
329,419,495,381,288,610, \\
453,473,566,123,529,1, \\
476,245,242,166\end{array}$ & $\begin{array}{l}(6.273056 \\
\mathrm{N}, \\
42.688145 \\
\mathrm{E}) / 370.11 \\
\mathrm{~km}\end{array}$ & 1684 & 1457 & 1.16 & 61.29 & $<.001$ \\
\hline
\end{tabular}

Table 4: Multivariable multilevel logistic regression analysis of high-risk fertility behavior among reproductive-age women in Ethiopia, $2016(n=11,022)$ 


\begin{tabular}{|c|c|c|c|c|c|}
\hline \multirow{4}{*}{ Variables } & \multirow{4}{*}{ Category } & \multirow{4}{*}{$\begin{array}{l}\text { Model (I) } \\
\text { AOR(95\% } \\
\text { CI) } \\
\text { Without } \\
\text { factor }\end{array}$} & \multirow{4}{*}{$\begin{array}{c}\text { Model(II) } \\
\text { AOR(95\% CI) } \\
\text { Individual-level } \\
\text { factor }\end{array}$} & \multirow{4}{*}{$\begin{array}{c}\text { Model (III) } \\
\text { AOR(95\% CI) } \\
\text { Community-level } \\
\text { factor }\end{array}$} & \multirow{4}{*}{$\begin{array}{c}\text { Model (III) } \\
\text { AOR(95\% CI) } \\
\text { Individual+Community } \\
\text { Level factor }\end{array}$} \\
\hline & & & & & \\
\hline & & & & & \\
\hline & & & & & \\
\hline \multirow[t]{2}{*}{ Sex of child } & Male & & Ref & & Ref \\
\hline & Female & & $0.94(0.85,1.03)$ & & $0.93(0.85,1.02)$ \\
\hline \multirow[t]{4}{*}{ Religion } & Orthodox & & Ref & & Ref \\
\hline & Muslim & & $1.35(1.19,1.52)$ & & $1.10(0.93,1.29)$ \\
\hline & Protestant & & $1.07(0.93,1.24)$ & & $1.08(0.89,1.30)$ \\
\hline & Others & & $1.14(0.82,1.59)$ & & $1.15(0.82,1.62)$ \\
\hline \multirow[t]{4}{*}{$\begin{array}{l}\text { Educational } \\
\text { status of } \\
\text { mother }\end{array}$} & $\begin{array}{l}\text { Unable to } \\
\text { read and } \\
\text { write }\end{array}$ & & Ref & & Ref \\
\hline & $\begin{array}{l}\text { Primary } \\
\text { education }\end{array}$ & & $0.69(0.62,0.78)$ & & $0.71(0.63,0.80) *$ \\
\hline & $\begin{array}{l}\text { Secondary } \\
\text { education }\end{array}$ & & $0.69(0.57,0.84)$ & & $0.73(0.60,0.89)^{*}$ \\
\hline & $\begin{array}{l}\text { Higher } \\
\text { education }\end{array}$ & & $0.76(0.59,0.99)$ & & $0.82(0.63,1.07)$ \\
\hline \multirow{2}{*}{$\begin{array}{l}\text { Occupational } \\
\text { status women }\end{array}$} & Working & & Ref & & Ref \\
\hline & $\begin{array}{l}\text { Not } \\
\text { working }\end{array}$ & & \multirow[t]{2}{*}{$0.99(0.89,1.09)$} & & $0.96(0.87,1.06)$ \\
\hline the mother & & & & & \\
\hline \multirow[t]{3}{*}{ Wealth index } & Poor & & Ref & & Ref \\
\hline & Middle & & $0.90(0.78,1.04)$ & & $0.95(0.82,1.10)$ \\
\hline & Rich & & $0.91(0.80,1.04)$ & & $0.98(0.85,1.13)$ \\
\hline \multirow[t]{2}{*}{$\begin{array}{l}\text { Media } \\
\text { exposure }\end{array}$} & $\begin{array}{l}\text { Has media } \\
\text { exposure }\end{array}$ & & Ref & & Ref \\
\hline & $\begin{array}{l}\text { No media } \\
\text { exposure }\end{array}$ & & $0.81(0.69,0.96)$ & & $0.83(0.70,1.004)$ \\
\hline \multirow{2}{*}{$\begin{array}{l}\text { Contraceptive } \\
\text { use }\end{array}$} & Yes & & \multicolumn{2}{|l|}{ Ref } & Ref \\
\hline & No & & $1.31(1.17,1.47)$ & & $1.25(1.12,1.40)^{*}$ \\
\hline
\end{tabular}




\begin{tabular}{|c|c|c|c|c|c|}
\hline \multirow{2}{*}{$\begin{array}{l}\text { Wanted } \\
\text { pregnancy }\end{array}$} & Yes & & Ref & & Ref \\
\hline & No & & $1.34(1.18,1.53)$ & & $1.40(1.23,1.59)^{*}$ \\
\hline \multirow{2}{*}{ Had ANC } & Yes & & Ref & & Ref \\
\hline & No & & $1.19(1.05,1.34)$ & & $1.19(1.05,1.35)^{*}$ \\
\hline \multirow[t]{2}{*}{ Still birth } & No & & Ref & & Ref \\
\hline & Yes & & $1.08(0.88,1.28)$ & & $1.07(0.90,1.27)$ \\
\hline \multirow{2}{*}{$\begin{array}{l}\text { Delivery } \\
\text { place }\end{array}$} & Institution & & Refe & & Ref \\
\hline & Home & & $0.99(0.88,1.12)$ & & $0.97(0.85,1.11)$ \\
\hline \multirow[t]{2}{*}{ Residence } & Urban & & & Ref & Ref \\
\hline & Rural & & & $1.65(1.43,1.90)$ & $1.26(1.04,1.51)^{*}$ \\
\hline \multirow{11}{*}{ Region } & Addis & & & Ref & Ref \\
\hline & Afar & & & $1.56(1.16,2.10)$ & $1.19(0.86,1.63)$ \\
\hline & Amhara & & & $0.81(0.61,1.08)$ & $0.72(0.53,0.96)^{*}$ \\
\hline & Oromia & & & $\begin{array}{l}1.18(0.89,1.57) \\
2.289\end{array}$ & $0.98(0.73,1.31)$ \\
\hline & Somalia & & & $2.29(1.73,3.05)$ & $1.70(1.24,2.32)^{*}$ \\
\hline & $\begin{array}{l}\text { Benishangul } \\
\text { Gumuz }\end{array}$ & & & $1.12(0.83,1.52)$ & $0.99(0.73,1.35)$ \\
\hline & SNNP & & & $1.05(0.79,1.39)$ & $0.93(0.69,1.26)$ \\
\hline & Gambela & & & $0.92(0.69,1.24)$ & $0.79(0.57,1.09)$ \\
\hline & Harari & & & $1.08(0.80,1.47)$ & $0.97(0.71,1.32)$ \\
\hline & Tigray & & & $1.07(0.811,1.43)$ & $1.03(0.77,1.39)$ \\
\hline & Dire Dawa & & & $1.43(1.05,1.94)$ & $1.22(0.88,1.68)$ \\
\hline \multicolumn{2}{|c|}{$\begin{array}{l}\text { Random effects (effects of } \\
\text { variation ) i.e measure of } \\
\text { variation for high-risk } \\
\text { fertility behavior }\end{array}$} & & & & \\
\hline \multicolumn{2}{|c|}{$\begin{array}{l}\text { Community level } \\
\text { variance(SE) }\end{array}$} & $0.188(0.032)$ & $0.062(0.024)$ & $0.064(0.023)$ & $0.039(0.024)$ \\
\hline \multicolumn{2}{|l|}{$\mathrm{p}$-vale } & $<0.001$ & $<0.001$ & $<0.001$ & $<0.001$ \\
\hline \multicolumn{2}{|l|}{ Deviance } & 11,372 & 11,146 & 11,202 & 11,092 \\
\hline \multicolumn{2}{|l|}{ ICC $\%$} & 5.4 & 1.8 & 1.91 & 1.18 \\
\hline \multicolumn{2}{|l|}{ PCV\% } & Reference & 67.03 & 65.97 & 79.26 \\
\hline
\end{tabular}




\begin{tabular}{|l|l|l|l|l|}
\hline MOR & 1.50 & 1.26 & 1.27 & 1.20 \\
\hline
\end{tabular}

* show a p-value less than 0.05 ,

Ref: reference category

\section{Figures}

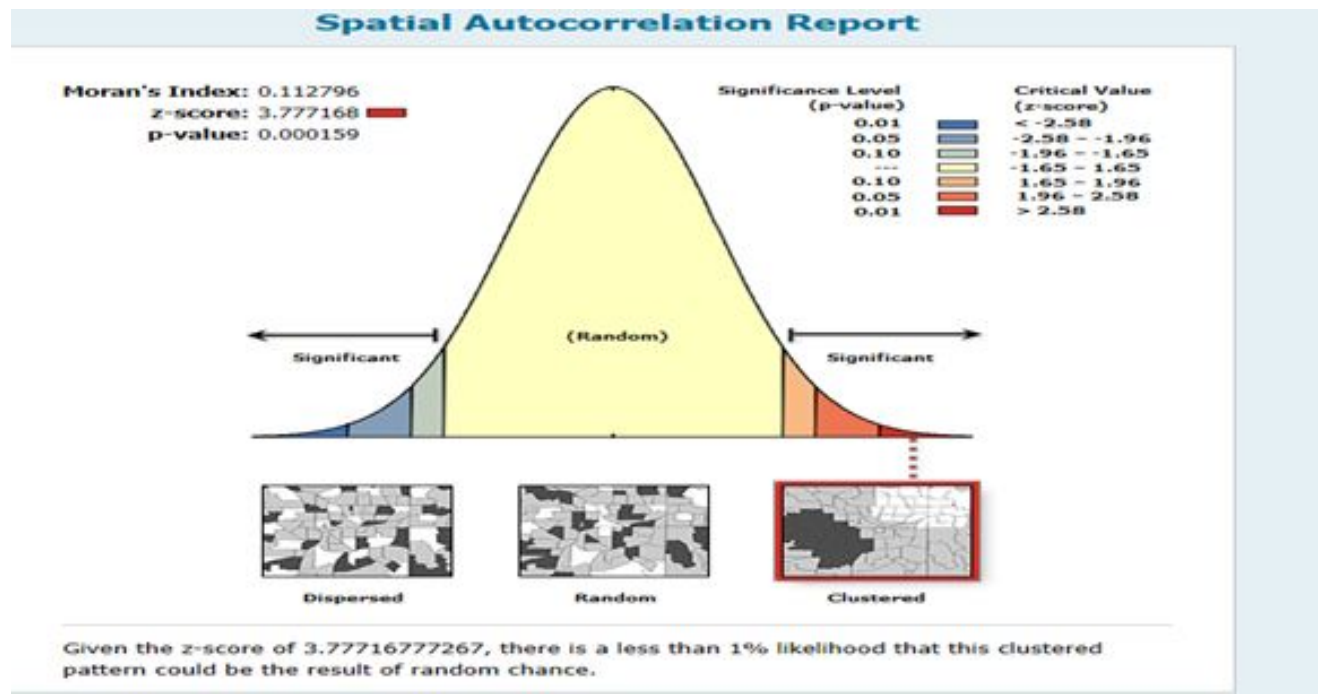

\section{Figure 1}

Spatial autocorrelation of high-risk fertility behavior of reproductive age group women in Ethiopia, 2016

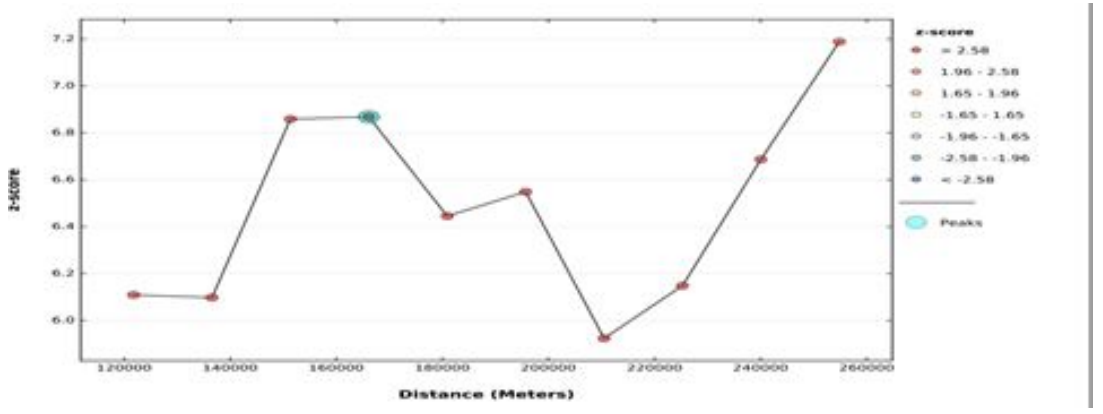

\section{Figure 2}

Incremental autocorrelation of high-risk fertility behavior in EHDS, 2016 


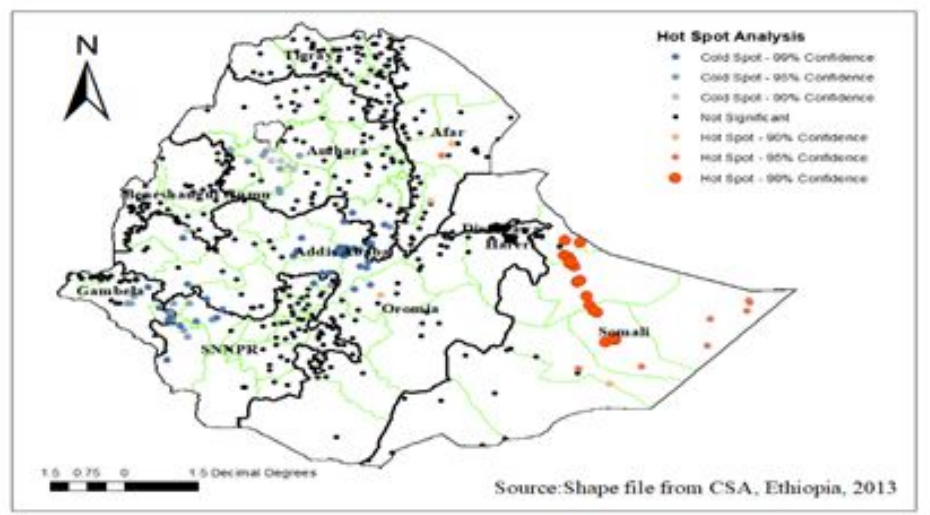

Figure 3

Hot spot analysis of high-risk fertility behavior among women within 5 years preceding the survey in Ethiopia, 2016

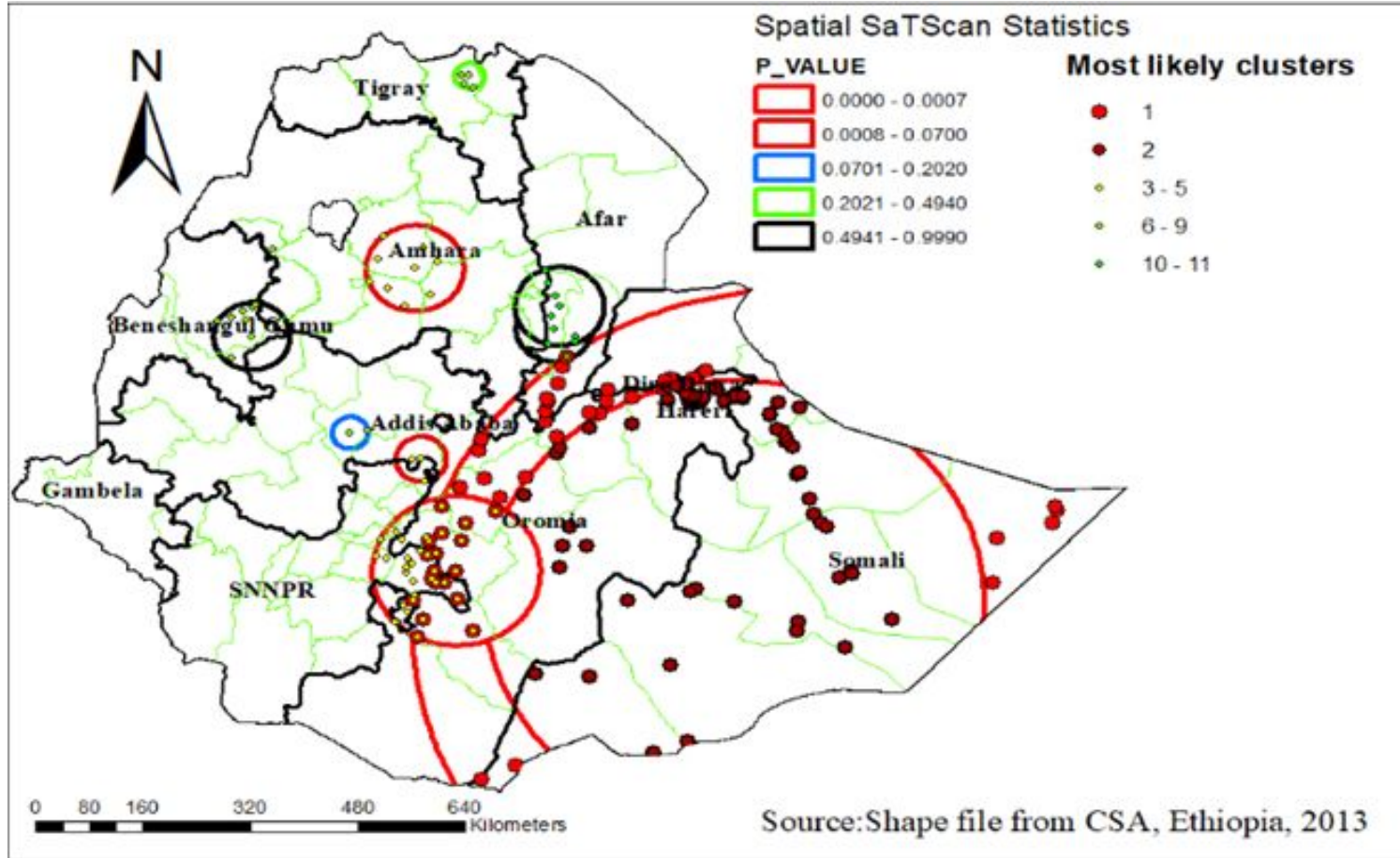

Figure 4

Spatial SaTScan analysis of high-risk fertility behavior among reproductive-age women in Ethiopia, 2016 


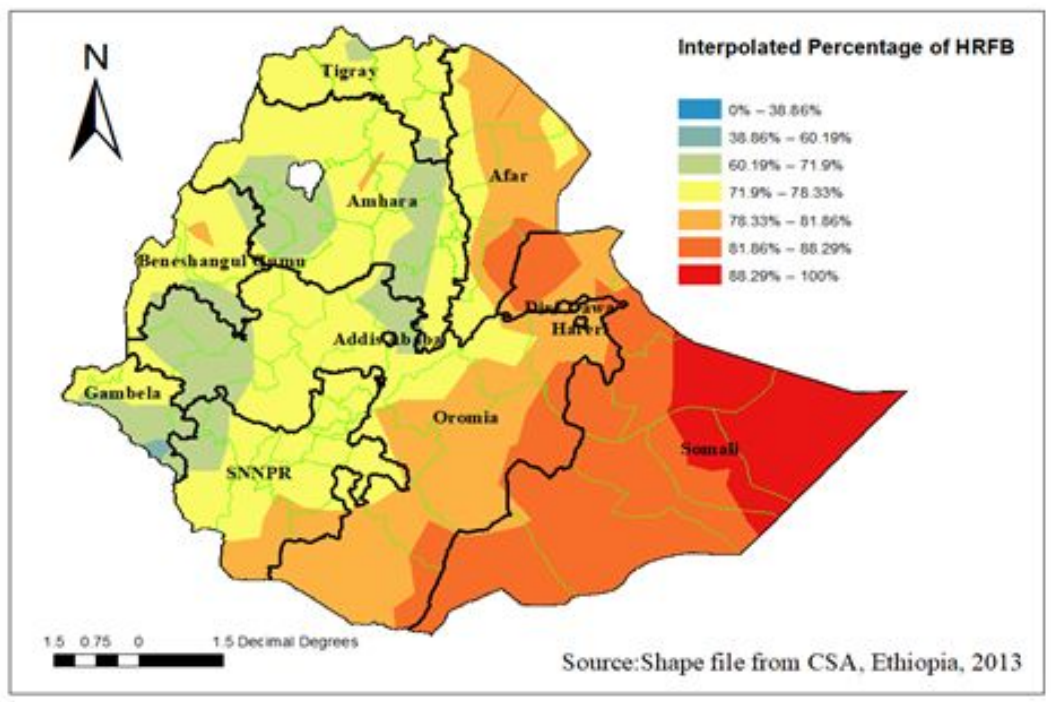

Figure 5

Interpolation of high-risk fertility behavior among reproductive-age women in Ethiopia, 2016. 